\title{
ESTRUTURAÇÃO GEOLÓGICA DA REGIÃO DA SERRA DO JUQUERIQUERÊ, SÃO SEBASTIÃO, SP ${ }^{*}$
}

\author{
G.A.C.Campanha ${ }^{1}$ \& H.H.Ens ${ }^{2}$
}

PALAVRAS-CHAVE: transpressão, zonas de cisalhamento, deformação dúctil.

CAMPANHA, G.A.C.; ENS, H.H. (1996) Estruturação geológica da região da Serra do Juqueriquerê,

São Sebastiåo, SP. Bol.IG-USP, Sér.Cient., 27:41-49.

\section{RESUMO}

O embasamento cristalino na região da serra do Juqueriquerê, São Sebastião, SP, é constituido de rochas para e ortoderivadas de médio e alto grau metamórfico, e rochas granitóides deformadas em intensidades variáveis. Na porção NW ocorrem rochas granitóides gnaissificadas (Granito Pico do Papagaio) e ao sul, separado pela zona de cisalhamento do Camburu, um conjunto de rochas predominantemente paraderivadas migmatizadas, com importante contribuiçåo de rochas metabasiticas. A estruturaçăo geral da área mostra uma disposiçăo em leque da foliação (xistosidade, bandamento gnáissico, foliação milonitica) em torno da Falha do Camburu. Esta caracteriza-se como uma zona de cisalhamento dúctil com movimentaçâo transcorrente destral. Para norte e para sul, a foliaçăo torna-se gradativamente menos inclinada, mostrando faixas de cisalhamento dúctil localizadas, com movimentaçăo obliqua ou de empurråo, e sentidos de deslocamento opostos, para norte no bloco norte, e para sul no bloco sul. Essa disposição em leque das estruturas em torno da Falha do Camburu, com a ocorrência de empurrōes divergentes nos blocos norte e sul, sugere um caráter transpressivo para a deformação dúctil que ocorreu na área, provavelmente entre o final do Neoproterozóico e o início do Paleozóico.

\section{ABSTRACT}

The crystalline basement in the region of the Juqueriquerê plateau, São Sebastião, $\mathrm{SP}$, is made up of para- and orthoderived high- to medium grade metamorphic rocks, and as by variably deformed and gneissic granitoid rocks. In the northern part of the region the Pico do Papagaio gneiss granitoid occurs, and to the south, separated by the Camburu transcurrent shear zone, is a set of mainly paraderived migmatitic rocks, with an important contribution of metabasic rocks. Structurally, the region exhibits a fan-like distribution of the foliation (schistosity, gneissic layering, mylonitic foliation) around the vertical Camburu shear zone, a dextral transcurrent ductile shear zone, Both to the north and south of this shear zone, the foliation flattens out, with localized thrust or oblique shear zones with displacement to the north in the northern block, and to the south in the southern block. This fan-like configuration of the structures around the Camburu shear zone, with divergent thrusts in the northern and southern blocks, suggests a transpressive character for the ductile deformation, which probably occurred between the end of the Neoproterozoic and the early Paleozoic.

\footnotetext{
Estudo patrocinado pela Financiadora de Estudos e Projetos - Finep.

'Departamento de Geologia Geral, Instituto de Geociências/USP, Såo Paulo, Brasil.

${ }^{2}$ Aluno Pós-Graduando IG/USP.
} 


\section{INTRODUÇÃO}

A área enfocada corresponde à saliência costeira do Juqueriquerê e abrange a serra homônima e a cidade de São Sebastião. Compreende partes das folhas topográficas à escala 1:50.000 de Pico do Papagaio, Maresias, Caraguatatuba e São Sebastião, sendo delimitada aproximadamente pelas longitudes $4522^{\prime}$ e $4545^{\prime} W$ e latitudes $2336^{\prime}$ e 2552 'S (Fig. 1).

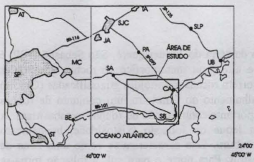

Figura 1 - Localização e acessos da área estudada. (AT) Atibaia; (TA) Taubaté; (SJC) São José dos Campos; (SLP) Săo Luís do Paraitinga; (JA) Jacareí; (PA) Paraibuna; (SA) Salesópolis; (UB) Ubatuba; (CA) Caraguatatuba; (SB) São Sebastião; (BE) Bertioga; (ST) Santos; (SP) Săo Paulo; (MC) Moji das Cruzes.

Sua principal via de acesso é a Rodovia Rio-Santos (BR 101/SP 55). A estrada Salesópolis a Caraguatatuba, embora não pavimentada, é o único acesso ao planalto do Juqueriquerê. Com suas variantes e trechos destinados à manutenção de oleoduto da Petrobrás, atravessa praticamente toda a área estudada.

Foi realizado um caminhamento o mais contínuo possível ao longo da estrada Salesópolis a São Sebastião, cruzando as principais unidades geológicas, geomorfológicas e estruturais, além de reconhecimento na região costeira e observaçōes em alguns pontos específicos, como ao longo da Falha do Cam- buru.

Durante os levantamentos de campo, foram feitas observações detalhadas das rochas aflorantes e efetuadas medidas das estruturas tectônicas, tais como foliações e lineações, indicadores cinemáticos, orientação de juntas, fraturas, espelhos de falha e de diques. No presente trabalho, apresenta-se as conclusões obtidas no tocante à geologia $\mathrm{e}$ estruturação do embasamento cristalino da área.

\section{GEOLOGIA}

A área estudada é constituida essencialmente por rochas do embasamento cristalino, de idade pré-cambriana. Ocorrem importantes enxames de diques do Jurássico Superior e Cretáceo Inferior. A área abrange também uma pequena porção do Maciço Alcalino da Ilha de São Sebastião, de idade neocretácea. Ocorrem ainda expressivas coberturas sedimentares quaternárias associadas às baixadas litorâneas (Fig. 2).

\section{LITOLOGIAS}

O embasamento cristalino da região estudada é constituído de rochas para e ortoderivadas de médio e alto grau metamórfico, e rochas granitóides deformadas e gnaissificadas em intensidades variáveis. A correlação destas rochas com unidades litoestratigráficas regionais, bem como suas idades, são assuntos controversos, percebendo-se na literatura diversas tendências. No mapa geológico do Estado de São Paulo (Bistrichi et al., 1981), as rochas metamórficas da saliência do Juqueriquerê são atribuídas ao Complexo Costeiro, de idade arqueana, porém com retrabalhamento e granitogênese policíclicas, o que justifica as idades brasilianas obtidas na maioria das datações geocrono- 


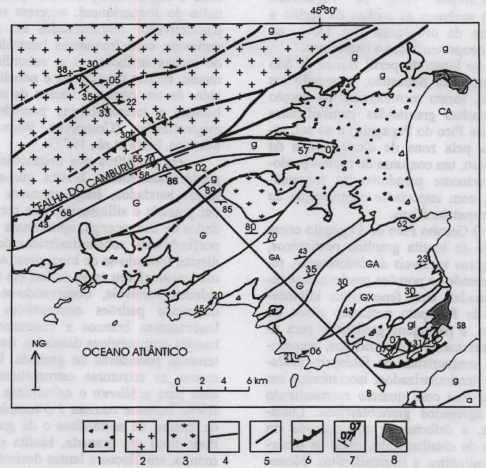

Figura 2 - Mapa geológico do Planalto do Juqueriquerê e áreas adjacentes: (1) sedimentos quaternários; (2) granitóides gnáissicos (Granito Pico do Papagaio); (3) metagabros, metadioritos e enderbitos parcialmente migmatizados (Complexo Bairro do Marisco); (4) Contatos; (5) zonas de cisalhamento transcorrente; (6) zonas de cisalhamento de cavalgamento; (7) atitudes de foliaçăo e lineaçăo de estiramento; (8) zonas urbanas; (a) rochas alcalinas sieníticas da Ilha de Săo Sebastião; (g) granitóides gnáissicos equigranulares, oftálmicos e nebulíticos; subordinadamente gnaisses, xistos e anfibolitos; (gi) leucogranito gnáissico com granada; $(G)$ biotita gnaisses e migmatito freqüentemente com granada e sillimanita; subordinadamente anfibolitos, kinzigitos, corpos nebulíticos e rochas cálcio-silicáticas; (GA) biotita gnaisses e migmatitos com freqüentes intercalações de anfibolitos; (GX) biotita gnaisses e xistos com intercalaçð̄es de quartzitos; (CA) Caraguatatuba; (SB) São Sebastião.

lógicas. Tal modelo tem sido adotado por diversos outros autores, destacandose Schobbenhaus et al. (1984), Chieregati et al. (1982), Hasui \& Oliveira (1984).

Já Machado Filho et al. (1983) preferem incluí-las no Complexo Paraiba do Sul, de idade arqueana. Por outro lado Tassinari (1988) elaborou diversos diagramas isocrônicos $\mathrm{Rb} / \mathrm{Sr}$ de rochas da saliência do Juqueriquerê, obtendo idades entre 600 e $650 \mathrm{Ma}$, interpretadas como época de evento metamórfico afetando rochas sedimentares ou metassedimentares pré-existentes. Estes protólitos teriam uma idade mínima de formação de $1.200 \mathrm{Ma}$ (Tassinari, 1988). 
Campos Neto \& Figueiredo (1995) atribuem às rochas da região a terrenos da orogênese Rio Doce, de idade neoproterozóica a cambriana.

Ao longo do perfil Bairro de São Lourenço-São Sebastião, levantado em detalhe, foram reconhecidas na porção NW rochas granitóides gnaissificadas (Granito Pico do Papagaio) e ao sul, separado pela zona de cisalhamento do Camburu, um conjunto de rochas predominantemente paraderivadas migmatizadas, com importante contribuição de rochas metabasíticas.

O Granito Pico do Papagaio constitui-se de biotita granitos porfiríticos, com graus variáveis de deformação, reconhecendo-se porções praticamente indeformadas, com fenocristais idiomórficos de feldspato potássico róseo ou branco, e passagens gradativas para tipos fortemente gnaissificados, apresentando megacristais de feldspato ovalados e lenticularizados, isorientados em matriz fina com quartzo recristalizado para agregados granoblásticos. Localmente, a deformação concentra-se em zonas de cisalhamento, onde se observam milonitos e ultramilonitos. Nestes pontos, a rocha pode apresentar-se bandada, com intercalações decimétricas a métricas de hornblenda gnaisse.

A Falha do Camburu constitui uma faixa de dezenas a centenas de metros de espessura de rochas miloníticas, ultramiloníticas, blastomiloníticas e protomiloníticas, predominantemente quartzo feldspáticas. Esta zona de cisalhamento pré-cambriana foi reativada durante o Juro-Cretáceo, com intrusão de espessos diques de rochas básicas, e mais recentemente, provavelmente no Terciário, com o abatimento do planalto do Juqueriquerê, dando origem a intercalações milimétricas a métricas de brechas cataclásticas silicificadas (Campanha \& Ens, 1992, 1993, Campanha et al., 1994).

Ao sul da Falha do Camburu, em toda a região compreendida pelo planalto do Juqueriquerê, ocorrem rochas paraderivadas migmatizadas em graus variáveis, com freqủentes intercalações de rochas anfibolíticas e, subordinadamente, rochas granitóides e nebulíticas, além de um pequeno núcleo de rochas básicas e intermediárias parcialmente migmatizadas (Complexo Bairro do Marisco, Silva et al., 1977).

Os protólitos dos migmatitos são predominantemente biotita gnaisses e xistos bandados, freqüentemente ricos em granada e sillimanita. Nas proximidades de Boiçucanga, apresentam ainda porfiroblastos subcentimétricos de cordierita, tratando-se de kinzigitos. A migmatização afetou estas rochas em intensidades variáveis, observando-se normalmente padrões estromáticos com leucossomas brancos e cinzentos, em bandas centimétricas dobradas, frequientemente portadoras de granada. Localmente, as estruturas estromáticas gradam para schlieren e nebulíticas. Uma feição bastante comum é o rompimento de bandas de anfibolitos e de gnaisses mais ricos em granada, biotita e sillimanita, em blocos e lentes decimétricos a métricos, com foliação interna discordante da foliação regional. Nos migmatitos mais evoluídos, estes blocos mais resistentes à fusão chegam a assemelhar-se a verdadeiros xenólitos.

Rochas anfibolíticas são comuns em toda a região ao sul da Falha do Camburu, parecendo concentrar-se, entretanto, em duas faixas; a primeira entre a praia do Juqueí e Boiçucanga, e a outra entre Maresias e a praia da Samiagem. Tais rochas ocorrem, em geral, como intercalaçōes centimétricas a decamétricas concordantes $e$, muitas vezes, boudinadas, lenticularizadas e segmentadas por veios neossomáticos e pegmatóides. Alguns corpos são, entretanto, tabulares e discordantes, tratandose de diques básicos pré-cambrianos anfibolitizados. 
Silva et al. (1977) reconheceram na região do Bairro do Marisco uma série de paleodiques anfibolitizados. Coutinho et al. (1991, 1992) identificaram na península do Baleeiro, em São Sebastião, um dique anfibolitizado, fortemente deformado, e um dique de micronorito anfibolitizado somente nas suas bordas. Próximo ao morro do Outeiro, nas imediações da praia de Guaecá foi observado um dique de anfibolito cortando quartzitos. Diques anfibolitizados foram identificados também no interior do Granito Pico do Papagaio, destacando-se um dique de $1,3 \mathrm{~m}$ de espessura, com bordas bandadas, parcialmente discordante, observado no Bairro de São Lourenço. Coutinho et al. (1991, 1992) reconheceram ainda nas redondezas da praia do Juqueí e praia Preta boudins de olivina websterito, enstatita fels, tremolita fels, etc. Estas rochas estão possivelmente relacionadas geneticamente com o Complexo Bairro do Marisco (Silva et al., 1977), que constitui um núcleo maior de rochas básicas e intermediárias granulitizadas e migmatizadas.

Na região de São Sebastião, ocorre ainda pequeno corpo concordante de rochas granitóides leucocráticas foliadas, ricas em granada. Estes granitóides cavalgam em baixo ângulo migmatitos estromáticos, com intercalaçőes de gnaisses, rochas anfibolíticas e granadasillimanita-biotita xistos.

Imediatamente ao sul da Falha do Camburu ocorre ainda faixa de rochas gnáissicas e granitóides deformadas, que parecem corresponder aos granitóides ou leptinitos de Caraguatatuba (Chieregati et al. 1982). Observaram-se nesta faixa granito-gnaisses equigranulares leucocráticos com intercalações de augen gnaisses, e mais raramente de anfibolitos.

\section{ESTRUTURAS}

As rochas pré-cambrianas aflorantes na área caracterizam-se pela presença quase constante de uma foliação metamórfica penetrativa em todas as escalas. Varia na intensidade de seu fabric, podendo normalmente ser caracterizada como uma xistosidade e/ou foliação gnáissica e, nas faixas mais deformadas, como uma foliação milonítica.

Dobras intrafoliais de porte decimétrico, associadas à essa foliação/bandamento gnáissico, podem ser observadas raramente nas rochas gnáissico-migmatíticas bandadas. Feições de boudinagens de corpos mais competentes, como anfibolitos, são mais comuns.

Essa foliação assume na área uma disposição tipicamente em leque (Fig. 3). Na porção central da área, em torno da Falha do Camburu, mostra posições empinadas, quase que verticalizadas. $\grave{A}$ medida que se caminha para sul, essa foliação vai mostrando mergulhos progressivamente menores, em geral para norte, até atingir uma zona de cisalhamento de baixo ângulo, junto à costa. Para norte, a foliação mostra disposição semelhante, porém com mergulho para sul, e afetada localmente por uma série de zonas de cisalhamento verticais de menor porte, com larguras da ordem de metros a dezenas de metros.

A Falha do Camburu, situada na porção central da estrutura em forma de leque, caracteriza-se, no tocante às suas deformações mais antigas, como zona de cisalhamento dúctil, balizada por milonitos, protomilonitos e ultramilonitos. As lineaçőes de estiramento observadas são sub-horizontais. A assimetria de porfiroclastos sugere movimentação de caráter transcorrente destral.

A Falha do Camburu apresenta-se ramificada para NE, sendo que um dos ramos parece corresponder à falha denominada Bertioga-Caraguatatuba por Chieregati et al. (1982) ou Quinhentos Reis por Melo \& Pires Neto (1977). O 

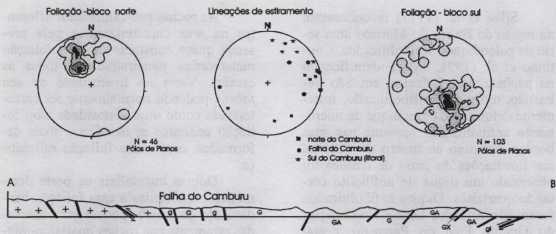

Figura 3 - Perfil geológico esquemático e estereogramas de atitudes medidas.

ramo que desvia para leste, acompanhando o curso do rio Camburu e adentrando a planície costeira de Caraguatatuba, é interpretado por Melo \& Pires Neto (1977) como sendo a falha principal.

$\mathrm{Na}$ aba sul da estrutura em leque, junto à região litorânea, ocorre outra zona de cisalhamento importante, mostrando-se bem aflorante nas pontas do Baleeiro e do Guaecá. Caracteriza-se por uma foliação de baixo ângulo, mergulhando para norte, e lineaçőes de estiramento obliquas ou no sentido do mergulho, com caimento para nordeste. Coloca um corpo de rocha leucogranitóide sobre migmatitos bandados. Feições intensas de dobramento, boudinage e deformação de diques básicos précambrianos são observadas na porção central dessa zona de cisalhamento. Numa faixa central ainda mais estreita, com espessura da ordem de metros, desenvolvem-se milonitos, ultramilonitos e protomilonitos. As atitudes de lineações de estiramento, assimetrias de porfiroclastos e de dobras de fluxo sugerem um movimento oblíquo, com a componente de cavalgamento para sul.

$\mathrm{Na}$ aba norte da estrutura em leque (ao norte da Falha do Camburu), observa-se situação similar, com outra zona de empurrão, porém com a foliação mergulhando para sudeste, e lineações de estiramento obliquas a direcionais. Os indicadores cinemáticos observados, constituídos por porfiroclastos assimétricos e estruturas $\mathrm{S} / \mathrm{C}$, sugerem movimentação oblíqua, com componente de empurrão para norte.

Essa passagem gradativa da atitude das estruturas através da megaestrutura em leque sugere mais um evento único de deformação, do que a sobreposição de dois eventos, como por exemplo uma movimentação inicial de baixo ângulo sobreposta por uma deformação de alto ângulo transcorrente.

A configuração em leque das estruturas em torno da Falha do Camburu, com passagem gradativa da posição da foliação, de alto ângulo na região central, para baixo ângulo nas abas norte e sul, sugere uma mega estrutura em flor positiva, e um caráter transpressivo para a deformação dúctil que ocorreu na área. Esta interpretaçăo é coerente com a disposição das lineações de estiramento e indicadores cinemáticos. Estes indicam uma movimentação essencialmente destral na porção central empinada da estrutura, passando a oblíqua nas suas abas norte e sul, com caráter divergente entre estas, com componente 
de empurrão para norte no bloco norte, e componente de empurrão para sul no bloco sul.

O regime transpressivo para a deformação associada ao sistema transcorrente do Cinturão Ribeira, com o desenvolvimento de megaestruturas em flor, tem sido proposto por diversos autores. Destacam-se ai os trabalhos de $\mathrm{Sa}$ dowski (1991), Ebert et al. (1991), Hackspacher et al. (1992), Machado \& Endo (1993), Correa Neto et al. (1993), Campanha \& Ens (1993), Ebert et al. (1993).

Este tipo de estruturação foge dos parâmetros definidos para zonas de cisalhamento com paredes planares, conforme definidas por Ramsay \& Graham (1970). Por outro lado, não existem por ora modelos gerais de fluxo de deformação dúctil em zonas de cisalhamento transpressivas consensualmente aceitos . Pode-se sugerir que a configuração aqui observada seja devida a uma partição da deformação, com concentração da componente de cisalhamento transcorrente na porção central, e uma maior importância dos componentes de empurrão divergentes nas abas da estrutura em leque.

\section{CONCLUSÕES}

A estruturação geral da área mostra uma disposição em leque da foliação (xistosidade, bandamento gnáissico, foliação milonítica) em torno da Falha do Camburu. Esta caracteriza-se como uma zona de cisalhamento dúctil com movimentação transcorrente destral. Para norte e para sul, a foliação torna-se gradativamente menos inclinada, mostrando faixas de cisalhamento dúctil localizadas, com movimentação oblíqua ou de empurrão, e sentidos de deslocamento opostos, para norte no bloco norte, e para sul no bloco sul.

A disposição em leque das estruturas em torno da Falha do Camburu, com a ocorrência de empurrões divergentes nos blocos norte e sul, sugere um caráter transpressivo para a deformação dúctil que ocorreu na área, provavelmente no final do Proterozóico Superior a início do Paleozóico.

\section{AGRADECIMENTOS}

Os autores agradecem ao Instituto de Pesquisas Tecnológicas - IPT, à Financiadora de Estudos e Projetos FINEP e ao Centro de Biologia Marinha da Universidade de São Paulo CEBIMAR, pelos apoios financeiro e operacional fornecidos, e ao Prof. Dr. Alberto Pio Fiori pelas críticas e sugestões dadas a este texto.

\section{REFERÊNCIAS BIBLIOGRÁFICAS}

BISTRICHI, C.A.; CARNEIRO, C.D. R.; DANTAS, A.S.L.; PONÇANO, W.L.; CAMPANHA, G.A.C.; NAGATA, N.; ALMEIDA, M.A.; STEIN, D.P.; MELO, M.S.; CREMONINI, A.C. (1981) Mapa Geológico do estado de São Paulo, 1:500.000. São Paulo, IPT. v. 2 . (Monografias IPT, 6).

CAMPANHA, G.A.C.; ENS, H.H. (1992) Análise morfotectônica integrada do Sudeste Brasileiro, área do Planalto do Juqueriquerê. São Paulo, IPT. 42 p. (relatório inédito 29991).

CAMPANHA, G.A.C.; ENS, H.H. (1993) Estrutura geológica na região de São Sebastião. In: SIMPÓSIO DE GEOLOGIA DO SUDESTE, 3., 1993. Boletim de resumos. Rio de Janeiro, SBG. p. 51-52.

CAMPANHA, G.A.C.; ENS, H.H.; PONÇANO, W.L. (1994) Análise morfotectônica do planalto do Juqueriquerê, São Sebastião. Revista Brasileira de Geociências, v.24, n.1, p. 32-42.

CAMPOS NETO, M.C.; FIGUEIRE- 
DO, M.C.H. (1995) The Rio Doce Orogeny, Southeastern Brazil. Journal of South American Earth Sciences, v. 8, n.2, 143-162.

CHIEREGATI, L.A.; GODOY, A.M.; THEODOROVICZ, A.; MENEZES, R.G.; CHIODI FILHO, C.; BATOLLA Jr., F. (1982) In: Projeto folhas Natividade da Serra e Caraguatatuba; relatório final. São Paulo, CPRM. v.1 (inédito).

CORREA NETO, A.V.; DAYAN, H.; VALENCCA, J.G.; CABRAL, A.R. (1993) Geologia e estrutura da zona de cisalhamento do rio Paraíba do Sul e adjacências, no trecho entre Três Rios (RJ) e Sapucaia (RJ). In: SIMPÓSIO DE GEOLOGIA DO SUDESTE, 3., Rio de Janeiro, 1993. Atas. Rio de Janeiro, SBG. p. 194 200.

COUTINHO, J.M.V.; ENS, H.H.; RODRIGUES, E.P. (1992) Petrography and field features of precambrian and mesozoic mafic dykes in southeastern Brazil. In: INTERNATIONAL GEOLOGICAL CONGRESS, 29., Kyoto, 1992. Field Trip Guide Book. Kyoto, Nagoa University. p.567.

COUTINHO. J.M.V.; ENS, H.H.; RODRIGUES, E.P.; TASSINARI, C.C.G. (1991) Mafic dyke swarms in the northern coast of São Paulo, Brazil (a preliminary report). In: INTERNERNATIONAL SYMPOSIUM MAFIC DYKES, São Paulo, 1991. Extended Abstracts. São Paulo, SBGq/SGP, p. 111-115.

EBERT, H.D.; NEVES, M.A.; HASUI, Y.; SZATMARI, P.; AIRES, J.R. (1993) Evolução dos cinturões de cisalhamento entre os blocos São Paulo, Vitória e Brasília através da tectônica colisional oblíqua: uma modelagem física. In: SIMPÓSIO NACIONAL DE ESTUDOS TECTÔNICOS, 4., Belo Horizonte, 1993. Anais. Belo Horizonte, SBG. p.254-
258.

EBERT, H.D; HASUI, Y; COSTA, J.B.S. (1991) O caráter transpressivo do cinturão transcorrente Rio Paraíba do Sul. In: SIMPÓSIO NACIONAL DE ESTUDOS TECTÔNICOS, 3., Rio Claro, 1991. Boletim de Resumos Expandidos. Rio Claro, SBG, p.139-141.

HACKSPACHER, P.C.; MORALES, N.; ZANARDO, A.; GODOY, A.M. OLIVEIRA, M.A.F.; ARTUR, A.C. (1992) A tectônica transcorrente transpressiva brasiliana da folha São Roque-SP. In: CONGRESSO BRASILEIRO DE GEOLOGIA, 37., São Paulo, 1992. São Paulo, SBG. v.2, p. 348-350.

HASUI, Y.; OLIVEIRA, M.A.D. (1984) Província Mantiqueira - setor central. In: ALMEIDA. F.F.M.; HASUI,Y. (eds.) O Pré-Cambriano do Brasil. São Paulo, Ed. Edgard Blücher. $378 \mathrm{p}$.

MACHADO FILHO, M; RIBEIRO, M.W.; GONZALEZ, S.R.; SCHENINI, C.A.; SANTOS NETO, A.; PALMEIRA, R.C.B.; PIRES, J.L.; TEIXEIRA, W.; CASTRO, H.E.F. (1983) Geologia. In: Projeto RADAMBRASIL. Folhas SF. 23/24. Rio de Janeiro/Vitória. MME, Rio de Janeiro. p.27-304. (Levantamento de Recursos Naturais, v. 32).

MACHADO, R.; ENDO, I. (1993) A megaestrutura em flor positiva do vale do rio Paraíba do Sul no Rio de Janeiro e suas implicações tectônicas regionais. In: SIMPÓSIO DE GEOLOGIA DO SUDESTE, 3, Rio de Janeiro, 1993. Atas. Rio de Janeiro, SBS p.208-213.

MELO, M.S.; PIRES NETO, A.G. (1977) Esboço geológico da província costeira entre as serras do Juqueriquerê e Parati, Estado de São Paulo. In: SIMPÓSIO DE GEOLOGIA REGIONAL, 1., São Paulo, 1977. Atas. São Paulo, SBG. p.303- 
323.

RAMSAY, J.G.; GRAHAM, R.H. (1970) Strain variation in shear belts.

Canadian Journal of Science, v.7, p. 786-813.

SADOWSKI, G.R. (1991) A megafalha de Cubatăo no Sudeste Brasileiro. Boletim IG-USP, Série Cientifica, v. 22 , p. $15-28$.

SCHOBBENHAUS, C.; CAMPOS, D.A.; DERZE, G.R.; ASMUS, H.E. (1984) Mapa geológico do Brasil e área oceânica adjacente; incluindo depósitos minerais, escala 1:2.500.000. Brasilia: MME/DNPM.

SILVA, A.T.S.F.; ALGARTE, J.P.;
CHIODI FILHO, C.; CHIODI, D.K.; FERNANDES, N.A. (1977) O Complexo Bairro do Marisco (Caraguatatuba, SP). In: SIMPÓSIO DE GEOLOGIA REGIONAL, 1., São Paulo, 1977. Atas. São Paulo, SBG. p. 74-90.

TASSINARI, C.C.G. (1988) As idades das rochas e dos eventos metamórfícos da porção sudeste do Estado de São Paulo e sua evolução crustal. São Paulo. São Paulo, 235p. (Tese - Doutorado) - Instituto de Geociências, Universidade de São Paulo.

G.A.C.Campanha - Instituto de Geociências, Universidade de São Paulo, Caixa Postal 11.348, CEP 05422-970, São Paulo, SP, Brasil. 